\title{
Capsule Commentary on Chen et al., "Impact of an Episode-Based Payment Initiative by Commercial Payers in Arkansas on Procedure Volume: an Observational Study"
}

\author{
Cason Pierce, MD, MA, FHM \\ Division of Hospital Medicine, Denver Health, University of Colorado Anschutz, Aurora, CO, USA.
}

J Gen Intern Med 35(2):622

DOI: $10.1007 / \mathrm{s} 11606-019-05496-4$

(c) Society of General Internal Medicine 2019

$\mathrm{T}$ he observational study by Chen et al. ${ }^{1}$ examined the effects of a mandated change from a fee-for-service (FFS) to an episode-based payment (EBP) reimbursement model on procedural volumes and the probability that commercially insured beneficiaries in Arkansas underwent four elective procedures: colonoscopy, tonsillectomy, cholecystectomy, and total joint replacement. They found only colonoscopy rates increased in a statistically significant manner in the post-intervention period. They concluded that transition to EBP increases some, but not all, elective procedures.

The authors used pooled data from adjacent states that did not implement EBP as a control and utilized a "difference-indifferences" (DD) analysis to minimize potential for confounder-driven results. For this approach to be valid, the control group must be well matched and should respond in the same way as the intervention group to unmeasured variables that impact the outcome. The authors importantly used a number of robustness checks to establish the control group was well matched. Validity also assumes that no other variable that could impact the outcome uniquely changes in the intervention group, simultaneous with the intervention. They less definitively establish there were no other important coincident changes in Arkansas at the time of the EBP reform. ${ }^{1}$ Importantly, DD can misestimate reform impact if reforms are announced before implementation and individuals can respond by changing behavior before implementation. ${ }^{2-4}$ If providers anticipate lower (or higher) future reimbursement, they may deliberately delay or accelerate procedures, biasing the authors' results in an unpredictable way.

Overall, the findings presented by Chen et al. are intriguing and may inform discussions about the potential impacts of change to EBP on procedural volumes. However, the conclusions should be interpreted cautiously. It remains possible these findings were driven by unmeasured coincident changes in Arkansas - creation in 2014 of patient-centered medical homes that promoted access to preventive care including colonoscopy ${ }^{1}$ - or deliberate acceleration/delay of procedures following announcement of the policy change. Regardless, it seems likely the reimbursement structure and rates of the EBP model, available provider capacity, and geographically specific practice patterns would impact procedural volume changes. ${ }^{5}$ These results, while interesting, may have limited generalizability.

Corresponding Author: Cason Pierce, MD, MA, FHM; Division of Hospital Medicine, Denver Health University of Colorado Anschutz, Aurora, CO, USA (e-mail: cason.pierce@dhha.org).

\section{Compliance with Ethical Standards:}

Conflict of Interest: The author declares that he has no conflict of interest.

Publisher's Note: Springer Nature remains neutral with regard to jurisdictional claims in published maps and institutional affiliations.

\section{REFERENCES}

1. Chen JL, Chernew ME, Fendrick AM, Thompson JW, Rose S. Impact of an Episode-Based Payment Initiative by Commercial Payers in Arkansas on Procedure Volume: An Observational Study. JGIM. https://doi.org/10. 1007/s11606-019-05318-7.

2. Angrist JD, Pischke J-S. Mostly harmless econometrics: An empiricist's companion. Princeton University Press; 2008.

3. Autor DH. Outsourcing at will: The contribution of unjust dismissal doctrine to the growth of employment outsourcing. $J$ Labor Econ. 2003;21(1):1-42.

4. Wing C, Simon K, Bello-Gomez RA. Designing difference in difference studies: best practices for public health policy research. Ann Rev Public Health. 2018;39.

5. Birkmeyer JD, et al. Understanding of regional variation in the use of surgery. Lancet. 2013;382(9898):1121-1129.

Publisher's Note Springer Nature remains neutral with regard to jurisdictional claims in published maps and institutional affiliations.

Published online November 12, 2019 